\title{
Ten kilohertz SCS for Treatment of Chronic Upper Extremity Pain (UEP): Results from Prospective Observational Study
}

This article was published in the following Dove Press journal: Journal of Pain Research

\author{
Abram Burgher' \\ Peter Kosek ${ }^{2}$ \\ Steven Surrett ${ }^{3}$ \\ Steven M Rosen ${ }^{4}$ \\ Todd Bromberg ${ }^{4}$ \\ Ashish Gulve $\mathbb{D D}^{5}$ \\ Anu Kansal ${ }^{5}$ \\ Paul $\mathrm{Wu}^{6}$ \\ W Porter McRoberts (iD ${ }^{6}$ \\ Ashish Udeshi $\mathbb{I D}^{7}$ \\ Michael Esposito ${ }^{7}$ \\ Bradford E Gliner (D) ${ }^{8}$ \\ Mona Maneshi ${ }^{8}$ \\ Anand Rotte ${ }^{8}{ }^{8}$ \\ Jeyakumar Subbaroyan ${ }^{8}$ \\ 'Hope Research Institute, Phoenix, AZ, \\ USA; ${ }^{2}$ Oregon Neurosurgery, Eugene, \\ OR, USA; ${ }^{3}$ Oregon Medical Group, \\ Eugene, OR, USA; ${ }^{4}$ Delaware Valley Spine \\ and Pain, Trevose, PA, USA; ${ }^{5}$ The James \\ Cook University Hospital, \\ Middlesbrough, UK; ${ }^{6} \mathrm{Holy}$ Cross \\ Hospital, Inc., Ft, Lauderdale, FL, USA; \\ ${ }^{7}$ Florida Pain Institute, Merritt Island, FL, \\ USA; ${ }^{8}$ Nevro Corp., Redwood City, \\ CA, USA
}

Background: Chronic upper extremity pain (UEP) has complex etiologies and is often disabling. It has been shown that $10 \mathrm{kHz}$ SCS can provide paresthesia-free and durable pain relief in multiple pain types and improve the quality of life of patients.

Objective: To gain additional evidence on the safety and effectiveness of $10 \mathrm{kHz}$ SCS for the treatment of chronic UEP.

Study Design: It was a prospective, multicenter, and observational study. The study was registered on ClinicalTrials.gov prospectively (clinical trial identifier: NCT02703818).

Setting: Multicenter.

Patients, Intervention and Main Outcomes: A total of 43 subjects with chronic UEP of $\geq 5 \mathrm{~cm}$ (on a $0-10 \mathrm{~cm}$ visual analog scale; VAS) underwent a trial of $10 \mathrm{kHz} \mathrm{SCS}$, and subjects with $\geq 40 \%$ pain relief received a permanent implant. All subjects had upper limb pain at baseline, while some had concomitant shoulder or neck pain. Subject outcomes were assessed for 12 months, and the primary outcome was the responder rate (percentage of subjects experiencing $\geq 50 \%$ pain relief from baseline) at three months.

Results: Thirty-eight subjects successfully completed the trial ( $88.3 \%$ success rate), 33 received permanent implants (five withdrew consent), and 32 had device activation (per protocol population). There were no paresthesias or uncomfortable changes in stimulation related to changes in posture during the study and there were no neurological deficits. Responder rates at 12 months for upper limb, shoulder, and neck pain in per protocol population $(\mathrm{N}=32)$ were $78.1 \%, 85.2 \%$, and $75.0 \%$, respectively. At 12 months, $84.4 \%$ of subjects were satisfied or very satisfied with 10 $\mathrm{kHz} \mathrm{SCS}$, and $38.7 \%$ either reduced or eliminated opioid usage.

Conclusion: This study further supports the effectiveness of $10 \mathrm{kHz}$ SCS for chronic UEP treatment and documents the safety profile of the therapy.

Clinical Trial Identifier: NCT02703818.

Keywords: $10 \mathrm{kHz}$ SCS, VAS, upper extremity pain, shoulder and upper limb pain

\section{Introduction}

Cervical spine disorders that cause pain in the upper extremities are frequently disabling and costly to treat. ${ }^{1,2}$ In the absence of neurological compromise, upper extremity pain (UEP) patients are typically managed with conservative care including physiotherapy or minimally invasive therapies such as epidural injections. If not effective, or when neurological sequelae indicate, surgical procedures including foraminotomy, and anterior or posterior cervical discectomy with or without fusion may be indicated. For specific etiologies, neurosurgical procedures such as lesioning of the dorsal root ganglia or entry zone may be considered.
Correspondence: Anand Rotte Nevro Corp., I800 Bridge Parkway, Redwood City, CA 94065, USA

Email anand.rotte@nevro.com 
Spinal cord stimulation (SCS) is a minimally invasive, reversible therapy that, in patients with previous lumbar spine surgery, was shown to provide greater reduction in leg pain compared to re-operation. ${ }^{3}$ Decades of clinical research suggests that SCS is a safe and effective option for certain types of pain that are refractory to conservative therapies. ${ }^{3-6}$ However, evidence in the literature supporting the use of traditional SCS to treat UEP is limited to small prospective studies, retrospective case reports and case series. $^{7-9}$ Moreover, traditional SCS is often accompanied by the uncomfortable paresthesias that may be exacerbated by head, neck, and upper limb position and movement.

Ten kilohertz SCS is known to provide paresthesia-independent pain relief and its efficacy has been demonstrated in different types of chronic pain conditions including low back and leg pain, nonsurgical back pain and complex regional pain syndrome (CRPS). ${ }^{10-13}$ Thus, the positional variation that compromises UEP relief with traditional SCS may be eliminated with $10 \mathrm{kHz}$ SCS. However, SCS devices including $10 \mathrm{kHz}$ SCS can have procedural/surgical complications such as infection, cellulitis, abscess, fever, sepsis, bleeding, cerebrospinal fluid leak, hematoma, seroma or thrombosis, epidural hemorrhage, impaired or inadequate wound healing, wound dehiscence and in rare instances spinal cord compression, nerve, nerve root, or spinal cord injury, paralysis and death. Ten kilohertz SCS was previously shown to provide pain relief and improve quality of life in patients with UEP in a small retrospective chart review. ${ }^{14}$ Recently, two prospective single arm studies reported the efficacy of $10 \mathrm{kHz}$ SCS in patients with upper limb and neck pain. ${ }^{15,16}$ Upper limb pain relief recorded in these studies was $62 \%$ and $79 \%$ and the corresponding responder rate was $77 \%$ and $89 \%$, whereas neck pain relief was $86 \%$ and $74 \%$ and the corresponding responder rate was $85 \%$ and $95 \%$, respectively. The objective of this prospective, multicenter, observational study was to gain additional effectiveness data of 10 $\mathrm{kHz}$ SCS for the treatment of chronic, intractable pain of the upper extremities. Along with safety and pain relief assessments, the study also reports data from overall quality of life assessments, patient satisfaction and changes in opioid medication usage.

\section{Materials and Methods}

\section{Ethics Statement}

The investigational protocol (20152890) and informed consent forms were reviewed and approved by an Institutional Review Board in the US (Western
Institutional Review Board) and ethics committee in the UK in January 2016, prior to patient enrollment. All aspects of the study were conducted in accordance with the Declaration of Helsinki and national, federal and local laws of pertinent regulatory authorities. The protocol was listed on ClinicalTrials.gov (NCT02703818) in January 2016 and was conducted as per STROBE guidelines.

\section{Study Design and Patient Population}

This was a prospective, postmarket, observational, multicenter study designed to provide evidence on the safety and effectiveness of $10 \mathrm{kHz}$ SCS in subjects with chronic, intractable pain of the upper extremities (upper limbs with or without concomitant neck or shoulder pain). Outcomes were assessed via standardized tests.

Subjects with chronic UEP, affiliated with or referred to the clinical sites, who were identified by the study investigators as candidates for SCS therapy, were recruited from multiple centers in the US ${ }^{5}$ and UK. ${ }^{1}$ Subjects who signed informed consent were assessed for eligibility based on the inclusion and exclusion criteria.

Key inclusion criteria were chronic, intractable UEP (visual analog scale, VAS $\geq 5$ out of $10 \mathrm{~cm}$ ) in adults aged 18 years and up, refractory to conservative therapy for a minimum of three months (previous conservative treatments included pain medications, physical therapy, spinal injections, pharmacological, and behavioral treatment); appropriate candidate for surgical procedures; and stable neurological status and pain medication (Box 1).

Major exclusion criteria were confounding pain in other areas (eg fibromyalgia, chronic headache); mechanical spine instability or significant cervical stenosis; active disruptive psychological or psychiatric disorder or other known condition significant enough to impact perception of pain (Box 2).

\section{Procedures}

Enrolled subjects who met all of the inclusion criteria and none of the exclusion criteria underwent a trial stimulation with $10 \mathrm{kHz}$ SCS (Senza System, Nevro Corp., Redwood City, CA, USA). Two octopolar leads (contact length: 3 $\mathrm{mm}$; inter-electrode distance: $5 \mathrm{~mm}$; lead materials: electrodes: Pt-Ir, platinum-iridium) were placed in the epidural space spanning $\mathrm{C} 2-\mathrm{C} 7$ cervical spine (entry from T2-T8) along the radiological/anatomical midline of the cervical spine to deliver the therapy (Figure 1). For selecting the optimal stimulation parameters and location during the trial, a simple bipole sweep was performed rostrocaudally 


\section{Box I Inclusion Criteria}

To participate in the study, subjects must have met all of the following inclusion criteria:

I. Have been diagnosed with chronic, intractable pain of an upper extremity related to the cervical spine and/or of neuropathic origin, which has been refractory to conservative therapy for a minimum of three months. Previous conservative therapy includes pain medications and physical therapy and may include other treatment modalities such as nerve root blocks or facet joint blocks/ denervations.

2. Have an average pain intensity (over a period of seven days) of an upper extremity of $\geq 5$ out of $10 \mathrm{~cm}$ on the VAS at enrollment.

3. Be on stable pain medications, as determined by the investigator, for at least 28 days prior to assessing pain intensity as described in inclusion criterion \#2, and be willing to stay on those medications with no dose adjustments until activation of the permanently implanted SCS device.

4. Be 18 years of age or older at the time of enrollment.

5. Be an appropriate candidate for the surgical procedures required in this study based on the clinical judgment of the implanting physician. 6. Be capable of subjective evaluation, able to read and understand English-written questionnaires, and are able to read, understand and sign the written inform consent in English.

7. Have stable neurological status measured by motor, sensory and reflex function as determined by the investigator.

8. Be willing and capable of giving informed consent.

9. Be willing and able to comply with study-related requirements, procedures, and visits.

10. Have adequate cognitive ability to use a patient programmer and recharger as determined by the investigator.

along the lead. Starting at the most rostral (distal) pair of contacts, bipole stimulation at $10 \mathrm{kHz}$ and $30 \mu \mathrm{s}$ was applied. Perception threshold testing was performed up to $5.0 \mathrm{~mA}$. Initial and maximum amplitudes were developed over time as the stimulation thresholds were unknown at the start of the study. Amplitude was initially set at 0.6 or $0.9 \mathrm{~mA}$ and increased up to 2.1 or 2.5 . If the subject did not achieve sufficient pain relief, amplitude was increased. If the amplitude reached the sensation threshold or $2.5 \mathrm{~mA}$ and the bipole location did not provide sufficient pain relief, the next set of bipoles were tested until the subject reported at least $40 \%$ pain relief or all possible bipoles had been tested. Subjects who experienced at least $40 \%$ reduction in their upper extremity pain during the trial compared to baseline were eligible for permanent device implantation with $10 \mathrm{kHz}$ SCS (Senza System, Nevro Corp.). Lower pain relief $(40 \%)$ was allowed during the trial primarily because the duration of the trial in many cases was expected to be not enough to fully optimize the therapy. IMPAACT guidelines suggest that $30 \%$ pain relief is clinically meaningful, ${ }^{17}$ so $40 \%$ cutoff was chosen during the trial only, as a reasonable screening criterion. However, $\geq 50 \%$ pain relief was required to be considered as a responder for therapy at follow-up assessment.

At the end of the trial, leads were removed, and subjects did not receive further stimulation until permanent implant of the SCS device. For the permanent implant, two leads were placed anatomically at approximately the same vertebral level as in the trial, anchored and then connected to an implantable pulse generator (IPG) placed in the subject's flank. Stimulation was delivered with a fixed waveform at $10 \mathrm{kHz}$ frequency, $30 \mu$ s pulse width, and amplitudes adjusted to maximize the subject's pain relief, typically $0.3-1.2 \mathrm{~mA}$. Choice of leads, contacts and vertebral level has been described previously. ${ }^{15}$ Briefly, the majority of the subjects had staggered octopolar leads placed midline in the cervical epidural space with the most cephalad lead at top of $\mathrm{C} 2$ and second lead at mid$\mathrm{C} 2$ vertebrae. A single bipole over the $\mathrm{C} 3-\mathrm{C} 4$ disc was identified as the most effective "sweet spot" in most subjects.

Assessments were performed at one, three, six, and 12 months after permanent implant through regular follow-up visits. Study protocol allowed programming adjustments throughout the follow-up period. As described previously, programming was usually done in a cephalad to caudad bipole search pattern starting at the tip of the most cephalad lead. ${ }^{15}$ This continued caudally, crossing to the second lead as needed until a positive response was obtained. After achieving a positive response in pain reduction, effort was made to get optimal relief by altering (increasing or decreasing) the amplitude. Before moving to the next amplitude or new bipole, a typical wait time of eight hours was allowed. ${ }^{15}$ Median time to reach $\geq 50 \%$ pain relief was three days during the trial and five days during the permanent implant phase. ${ }^{15}$ During the study, 10 subjects with a permanently implanted device made 20 unscheduled visits for reprogramming and the median of the number of programming sessions in the study was two (max, 4; $\min , 0)$.

\section{Intent-to-Treat (ITT) and per Protocol (PP) Analysis Populations}

The ITT population was defined as all subjects who were intended for a trial stimulation with $10 \mathrm{kHz}$ SCS (43 subjects). PP population was defined as those ITT 


\section{Box 2 Exclusion Criteria}

To participate in the study, subjects must not have met any of the following exclusion criteria:

I. Have a medical condition or pain in other area(s), not intended to be treated with SCS, that could interfere with study procedures, accurate pain reporting, and/or confound evaluation of study endpoints, as determined by the investigator (such as primary headache diagnosis and fibromyalgia). 2. Have a current diagnosis of a progressive neurological disease such as multiple sclerosis, chronic inflammatory demyelinating polyneuropathy, rapidly progressive arachnoiditis, brain or spinal cord tumor, central deafferentation syndrome, or acute herniating disc as determined by the investigator.

3. Have a current diagnosis or condition such as a coagulation disorder, bleeding diathesis, platelet dysfunction, progressive peripheral vascular disease or uncontrolled diabetes mellitus that presents excess risk for performing the procedure as determined clinically by the investigator. 4. Have a condition that would significantly increase perioperative risk including severely diminished functional capacity due to underlying cardiac/ pulmonary disease, symptomatic uncontrolled severe hypertension, symptomatic uncontrolled chronic obstructive pulmonary disease, being severely immunocompromised, or any other condition that the investigator determines would significantly increase perioperative risk.

5. Have an active systemic or location infection.

6. Have mechanical spine instability detected by flexion/extension films as determined by the investigator (imaging is required for this determination and must have been done within the past six months).

7. Have significant cervical stenosis, objective evidence of epidural scarring and/or any signs or symptoms of myelopathy as determined by MRI conducted within the past 12 months (as determined by the investigator).

8. Any previous history of surgery on the posterior elements (laminectomy, posterior fusion) resulting in a compromised epidural space (as determined by the investigator).

9. Be benefitting from an interventional procedure and/or surgery to treat upper limb pain (subjects should be enrolled at least 30 days from last benefit).

10. Have an existing drug pump and/or another active implantable device (switched on or off) such as a pacemaker or other SCS devices.

I I. Have a condition currently requiring or likely to require the use of whole body MRI or diathermy.

12. Have metastatic malignant disease or active local malignant disease.

13. Have a life expectancy of less than one year.

14. Be pregnant (if female and sexually active, subject must be using a reliable form of birth control, be surgically sterile or be at least two years postmenopausal).

I5. Have within six months of enrollment a significant untreated addiction to dependency producing medications, alcohol or illicit drugs (as determined by the investigator).

16. Be concomitantly participating in another clinical study.

17. Be involved in an injury claim under current litigation.

18. Have a pending or approved worker's compensation claim.

19. Have evidence of an active disruptive psychological or psychiatric disorder or other known condition significant enough to impact perception of pain, compliance of intervention and/or ability to evaluate treatment outcome, as determined by a psychologist.

subjects who received an IPG implant (after completing a successful screening trial), had their device activated, and completed at least three months of follow-up $(32$ subjects). Safety results are presented for all ITT subjects, while efficacy results are reported for PP subjects, which closely reflects clinical practice.

\section{Data Collection and Statistics}

Data were collected by independent clinic personnel from the study subjects and recorded in case report forms (CRFs) during prespecified follow-up assessments. The collected data was monitored and transferred into data listings using SAS 9.4 program and then into Excel $^{\mathrm{TM}}$ spreadsheets by the sponsor's team according to ICHGCP, ISO14155 and 21 CFR 11 guidelines. Researchers from the sponsor institution were also responsible for the data analysis and presentation. Considering the study sample size (Supplementary Digital Content. Methods 1) and the fact that data did not always have a normal distribution (determined by goodness of fit test using Excel), descriptive analysis of continuous variables included median and lower-higher quartiles (Q1-Q3). Categorical variables were reported as counts and percentages. All the outcomes (Supplementary Digital Content. Methods 2) were analyzed longitudinally and missing data was estimated using "last observation carried forward" (LOCF) approach. ${ }^{18}$ Rationale for choosing LOCF approach is discussed in Supplementary Digital Content. Methods 3. All the statistical analysis was performed using Excel. Two-tailed paired $t$-test was used for comparing two groups and a $p$-value $<0.05$ was considered as significant. 


\section{A.Study flowchart}
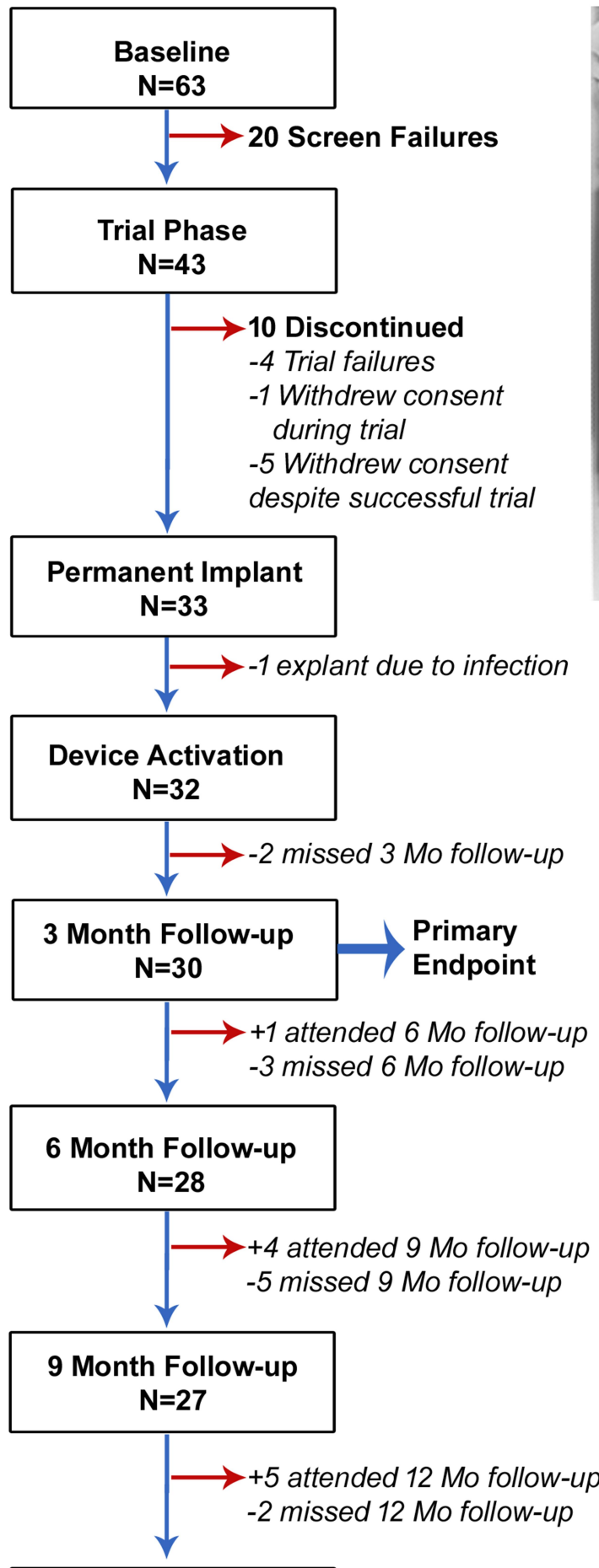

12 Month Follow-up

$\mathrm{N}=\mathbf{3 0}$

\section{B.Lead placement images}
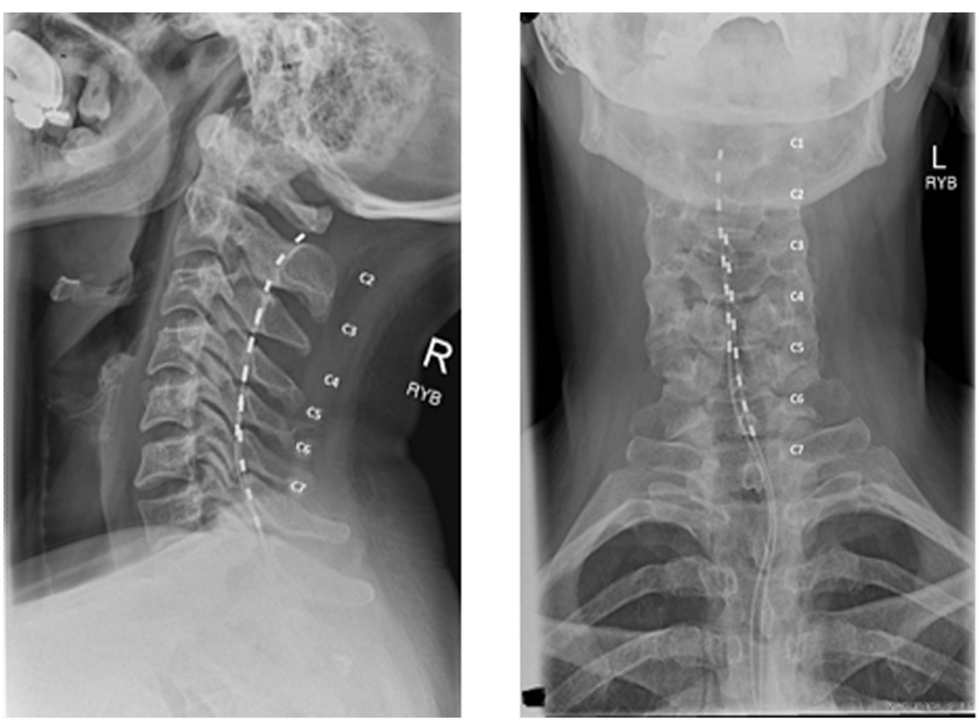

\section{C. $10 \mathrm{kHz}$ Waveform}

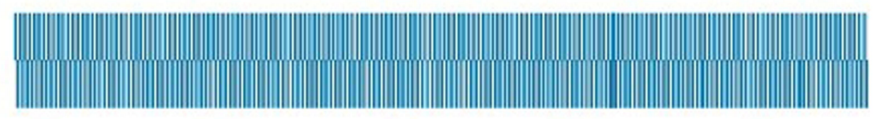

Figure I Study design; (A) study flowchart; (B) lead placement; (C) $10 \mathrm{kHz}$ Waveform; (D) $10 \mathrm{kHz}$ SCS device and leads. 


\section{Results}

\section{Study Population}

Flow of subjects in the study is detailed in Supplementary Digital Content. Results 1. Briefly, out of 43 trial subjects, $38(88.3 \%)$ had $\geq 40 \%$ relief in UEP (Figure 1). Of the 38 subjects who were eligible to receive permanent implant, five withdrew consent despite successful trial due to reasons including denial of insurance coverage. The remaining 33 subjects received a permanent implant and one had a device explanted before activation due to infection. Among the 32 PP subjects with upper limb pain, 24 (75.0\%) who also had concomitant neck pain (baseline VAS score of $\geq 5.0 \mathrm{~cm}$ ) were included in the neck pain subset and 27 (84.4\%) who also had concomitant shoulder pain (baseline VAS score of $\geq 5 \mathrm{~cm}$ ) were included in the shoulder pain subset.

\section{Demographics}

Baseline demographics and clinical characteristics of the PP population are shown in Table 1. Briefly, median age of the subjects at the time of enrollment was 47.0 years (range: 27.0-70.0), 65.6\% were female and the median time since diagnosis was 9.6 years (range: $1.0-30.0$ ). At baseline, median pain VAS score was $8.0 \mathrm{~cm}$ for upper limbs, $8.8 \mathrm{~cm}$ for neck, and $8.3 \mathrm{~cm}$ for shoulder. Opioids were used by $96.9 \%$ of subjects.

\section{Safety}

For the ITT population, there were no stimulation-related neurological deficits reported. There were no paresthesias or uncomfortable changes in stimulation related to changes in posture during the study. Neurological assessments of 30 subjects who completed the 12-month visit showed "no change" in neurological function in 29 subjects (96.7\%) and "improvement" in neurological function in 1 subject (3.3\%) compared to baseline.

There were eight study-related adverse events (AEs). Six procedure-related AEs occurring in four subjects included hematoma, headache, implant site infection, medical device site hemorrhage, musculoskeletal pain, and pain in extremity (one each). All the procedurerelated AEs except headache occurred during the permanent implant phase. All but one AE resolved without any sequalae by study completion. The ongoing AE was mild procedure-related (as judged by the investigator) musculoskeletal pain in the right shoulder, which was treated conservatively using Diclofenac Sodium
Table I Baseline Demographics and Clinical Characteristics for PP Subjects

\begin{tabular}{|c|c|}
\hline Characteristics & $\mathbf{N}=32$ \\
\hline \multicolumn{2}{|l|}{ Gender - N (\%) } \\
\hline Female & $21(65.6 \%)$ \\
\hline Male & I I (34.4\%) \\
\hline \multicolumn{2}{|l|}{ Age (years) at enrollment } \\
\hline Median & 46.5 \\
\hline Range & 27.0 to 70.0 \\
\hline \multicolumn{2}{|l|}{ Years since diagnosis } \\
\hline Median & 9.6 \\
\hline Range & 1.0 to 30.0 \\
\hline \multicolumn{2}{|l|}{ Diagnosis $^{a}-\mathbf{N}(\%)$} \\
\hline Chronic intractable upper limb pain & $32(100 \%)$ \\
\hline Chronic intractable upper limb and neck pain & $24(75.0 \%)$ \\
\hline Chronic intractable upper limb and shoulder pain & $27(84.4 \%)$ \\
\hline \multicolumn{2}{|l|}{ Upper limb pain - N (\%) } \\
\hline Bilateral & $23(71.9 \%)$ \\
\hline Unilateral & $9(28.1 \%)$ \\
\hline \multicolumn{2}{|l|}{ Pain etiology ${ }^{a}-\mathbf{N}(\%)$} \\
\hline Radiculopathy & $2 \mathrm{I}(65.6 \%)$ \\
\hline Spondylosis & $18(56.3 \%)$ \\
\hline Degenerative disc disease & $15(46.9 \%)$ \\
\hline Previous spine surgery & II (34.4\%) \\
\hline Other chronic pain & II (34.4\%) \\
\hline Mild or moderate spinal stenosis & $10(31.3 \%)$ \\
\hline Other neuropathic pain & $8(25.0 \%)$ \\
\hline CRPS I and/or II & $6(18.6 \%)$ \\
\hline Spondylolisthesis & $3(9.4 \%)$ \\
\hline Baseline use of opioids - N (\%) & $31(96.9 \%)$ \\
\hline \multicolumn{2}{|l|}{ Baseline VAS in cm (Median: Q I-Q3) } \\
\hline Upper limb pain & $8.0(7.2-8.6)$ \\
\hline Shoulder pain & $8.3(7.2-9.1)$ \\
\hline Neck pain & $8.8(8.0-9.2)$ \\
\hline
\end{tabular}

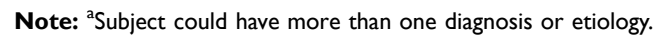

(Voltaren) 1\% transdermal gel, PRN. This subject decided to continue the therapy and declined explant. Two AEs categorized as possibly related to stimulation/ therapy occurring in two subjects included headache and unilateral pain in the extremity, both resolved with reprogramming (one each). There were two procedurerelated serious adverse events (SAEs) occurring in one subject, which occurred after permanent implant, a hematoma at the site of surgery and an implant site infection, which resulted in explant of the device. Both were resolved without sequelae following aspiration of the wound and prophylactic antibiotic treatment. 


\section{Pain Relief}

Baseline median VAS scores of $8.0,8.8$, and $8.3 \mathrm{~cm}$ for upper limb, neck, and shoulder pain, respectively, were significantly reduced to $1.0,1.3$, and $1.2 \mathrm{~cm}$ at the threemonth assessment $\left(p=7.2 \times 10^{-15}, 4.6 \times 10^{-9}, 1.6 \times 10^{-11}\right.$ respectively compared to baseline). At 12 months, median VAS scores were significantly reduced to $1.2,1.2$, and 1.4 $\mathrm{cm}$ for upper limb, neck, and shoulder pain, respectively (Figure 2A; $p=1.4 \times 10^{-15}, 6.8 \times 10^{-10}, 4.2 \times 10^{-11}$ respectively compared to baseline). Pain relief in individual subjects for upper limb, neck, and shoulder at 12 months compared to baseline is reported in Figure 2B, C, and D, respectively. Median percentage pain relief at three months compared to baseline was $88.0 \%$ for upper limb, $87.5 \%$ for neck and $87.6 \%$ for shoulder. Pain reductions were maintained through follow-ups and median pain reduction at 12 months compared to baseline was $86.2 \%$ for upper limb, $85.7 \%$ for neck and $86.3 \%$ for shoulder.

\section{Responder Rates}

In the PP population, responder rate at three-months was 81.3\% $(\mathrm{N}=26 / 32), 77.8 \%(\mathrm{~N}=21 / 27)$ and $70.8 \%(\mathrm{~N}=17 / 24)$ for upper limb, shoulder and neck pain, respectively, which sustained through the 12-month follow-up period (Figure 2E).

\section{Remitter Rates}

Subjects with VAS scores $\leq 3 \mathrm{~cm}$ for six months at the time of follow-up assessments were defined as remitters. ${ }^{19}$ Remitter rate in PP population at 12 months was $78.1 \%(\mathrm{~N}=25 / 32), 77.8 \%(\mathrm{~N}=21 / 27)$ and $62.5 \%$ $(\mathrm{N}=15 / 24)$ for upper limb, shoulder and neck pain respectively (Figure 2F).

\section{Short Form McGill Pain Questionnaire}

Ten kilohertz SCS therapy resulted in significant improvement $\left(p=2.1 \times 10^{-7}, \mathrm{p}=1.4 \times 10^{-8}, p=8.4 \times 10^{-7}, p=1.1 \times 10^{-6}\right.$, $\left.p=8.6 \times 10^{-9}\right)$ in all components of SF-MPQ scores including "continuous pain", "intermittent pain", "neuropathic pain", 'affective descriptors' and "total score" at three months, which further improved at 12 months (Figure 3).

\section{Improvement in Disability and Quality of Life}

Compared to baseline, pain disability index (PDI) score significantly improved $\left(p=1.4 \times 10^{-7}\right)$ by 32.0 points $(3.4 \times$ minimum clinically important difference, MCID) at three months. Similarly, disabilities of the arm, shoulder and hand (QuickDASH) score significantly improved $\left(p=1.5 \times 10^{-8}\right)$ by 40.9 points and global assessment of functioning (GAF) score significantly improved $\left(p=1.2 \times 10^{-6}\right)$ by 20.0 points at three months compared to baseline. At 12-month endpoint, PDI score improved by 30.5 points, Quick-DASH by 36.4 points, and GAF by 19.5 points (Figure $4 A-C$ ). The 12-item Short Form Health Survey (SF-12) PCS subscale scores significantly improved $\left(p=2.7 \times 10^{-6}\right)$ by 12.3 points and SF-12 MCS subscale improved significantly ( $p=0.004)$ by 6.8 points at 12 -month endpoint assessment (Figure 4D).

At three months, subjects reporting global impression of change (GIC)s "a great deal better", "better", or "moderately better" were $75.0 \%(\mathrm{~N}=24 / 32)$, which was sustained at 12-month assessment (Figure 5A and B). Similarly, clinicians reporting GIC as "a great deal better", "better", or "moderately better" were $71.9 \%(\mathrm{~N}=23 / 32)$ at three months, which increased to $78.1 \%(\mathrm{~N}=25 / 32)$ at the 12-month endpoint assessment (Figure 5C and D).

\section{Sleep}

Ten kilohertz SCS treatment reduced scores for all the three questions of the three-item pain and sleep questionnaire (PSQ-3), including how often subjects have trouble falling asleep due to pain, how often they are awakened due to pain in the night, and how often they are awakened due to pain in the morning (Supplementary Digital Content. Table S1). Global PSQ-3 score was significantly reduced $\left(p=7.8 \times 10^{-7}\right)$ from 25.1 at baseline to 8.6 at three months (16.5 reduction). The impact of pain on sleep continued to decrease over the study period, with a global score of 5.5 at 12 months (Figure 6A).

\section{Satisfaction}

At three months, $75.0 \%(\mathrm{~N}=24 / 32)$ of the subjects reported being "satisfied" or "very satisfied" with $10 \mathrm{kHz}$ SCS, which increased to $84.4 \%(\mathrm{~N}=27 / 32)$ at 12 months (Figure 6B).

\section{Medication Usage}

At baseline, 31 subjects in the PP (96.9\%) were taking an opioid medication (Table 1) and dose information was available from $24(75.0 \%)$ subjects. At three months, three subjects eliminated opioids, seven subjects decreased their opioid dose, 14 subjects had no change in opioid use and four subjects increased their opioid dose. At 12 months, three subjects eliminated opioids, nine subjects decreased their opioid dose, 11 subjects had no change in 
A

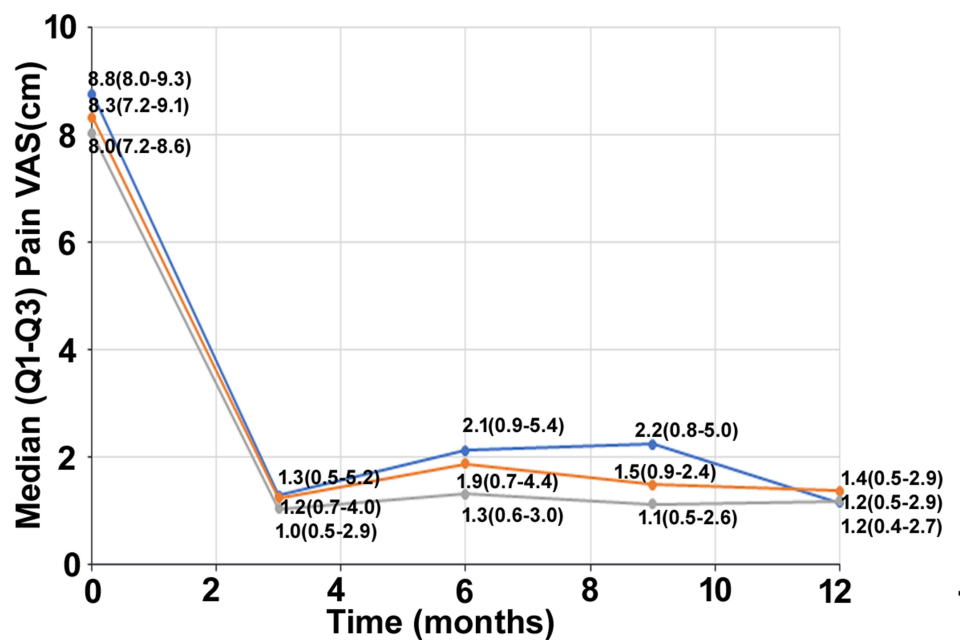

- Neck - Shoulder - Upper Limb

C
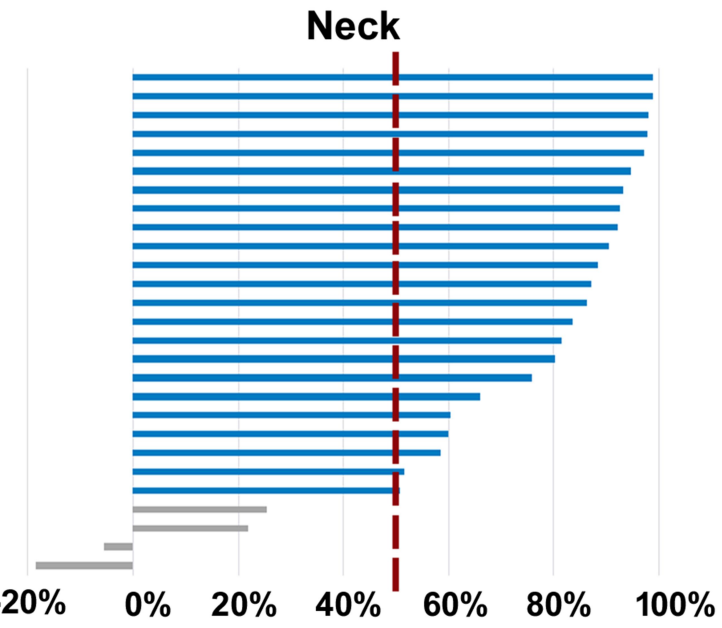

E

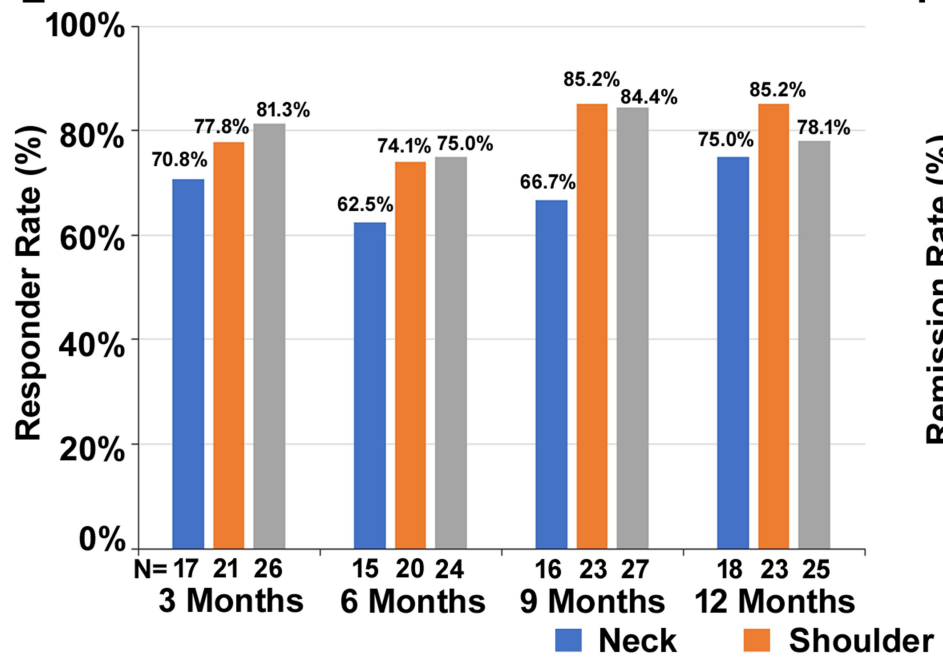

F
B

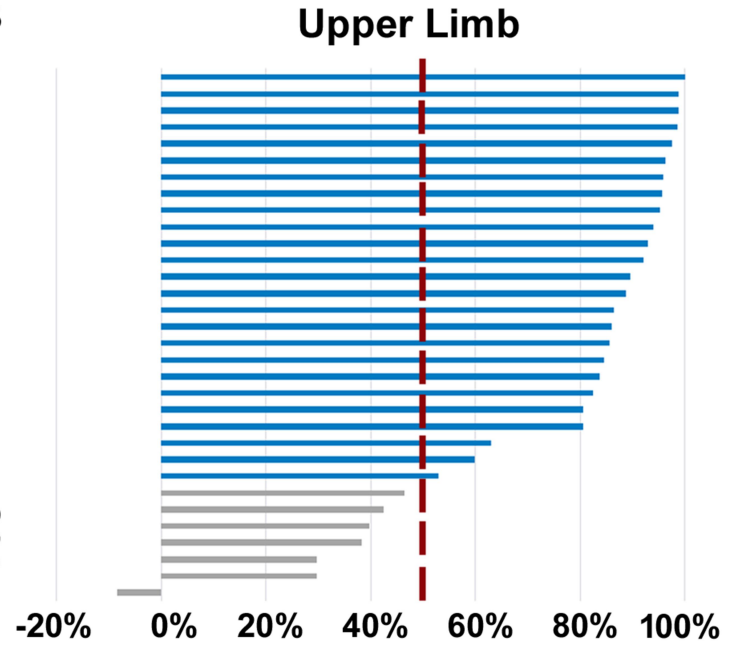

D

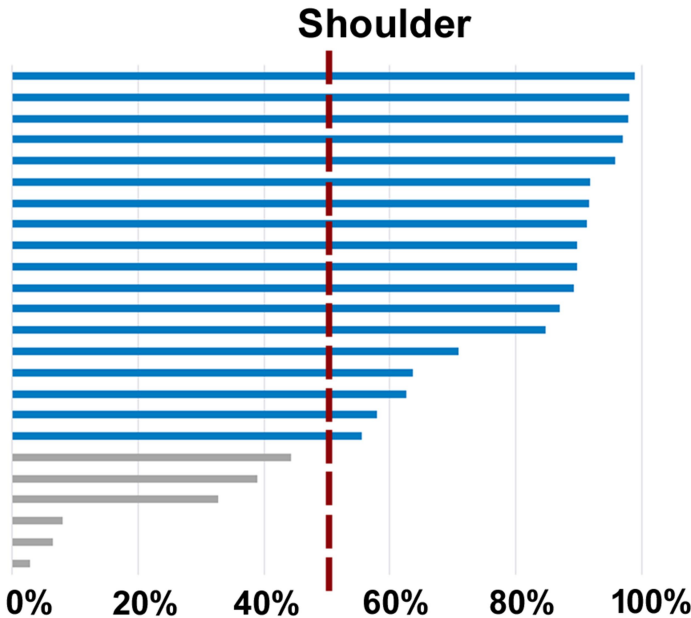

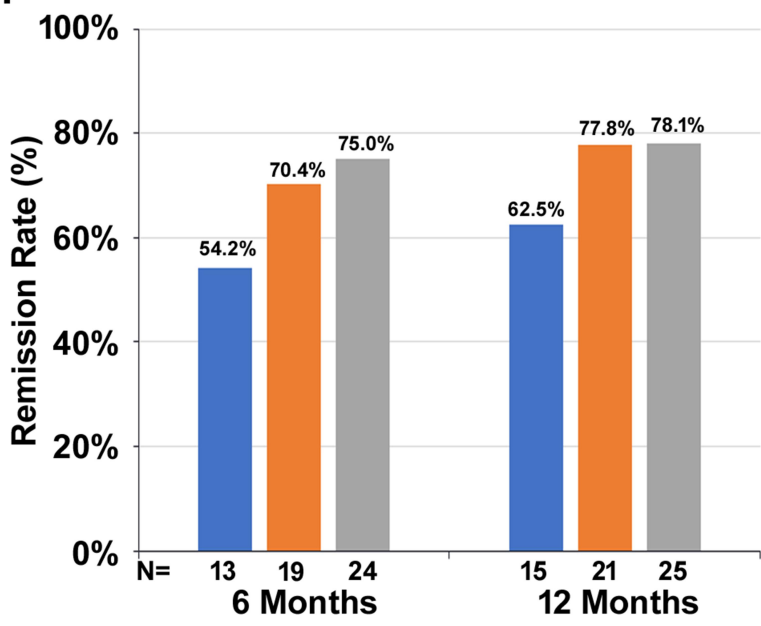

Upper Limb

Figure 2 Sustained relief from UEP with $10 \mathrm{kHz}$ SCS; (A) VAS pain scores (median QI-Q3), (B-D) Tornado chart for upper limb, shoulder, and neck pain relief in individual subjects at 12 months, (E) Responder rates with responder defined as $\geq 50 \%$ pain relief, (F) Remitter rates at six months and 12 -months with remitter defined as $\leq 3.0 \mathrm{~cm}$ VAS for six months. 


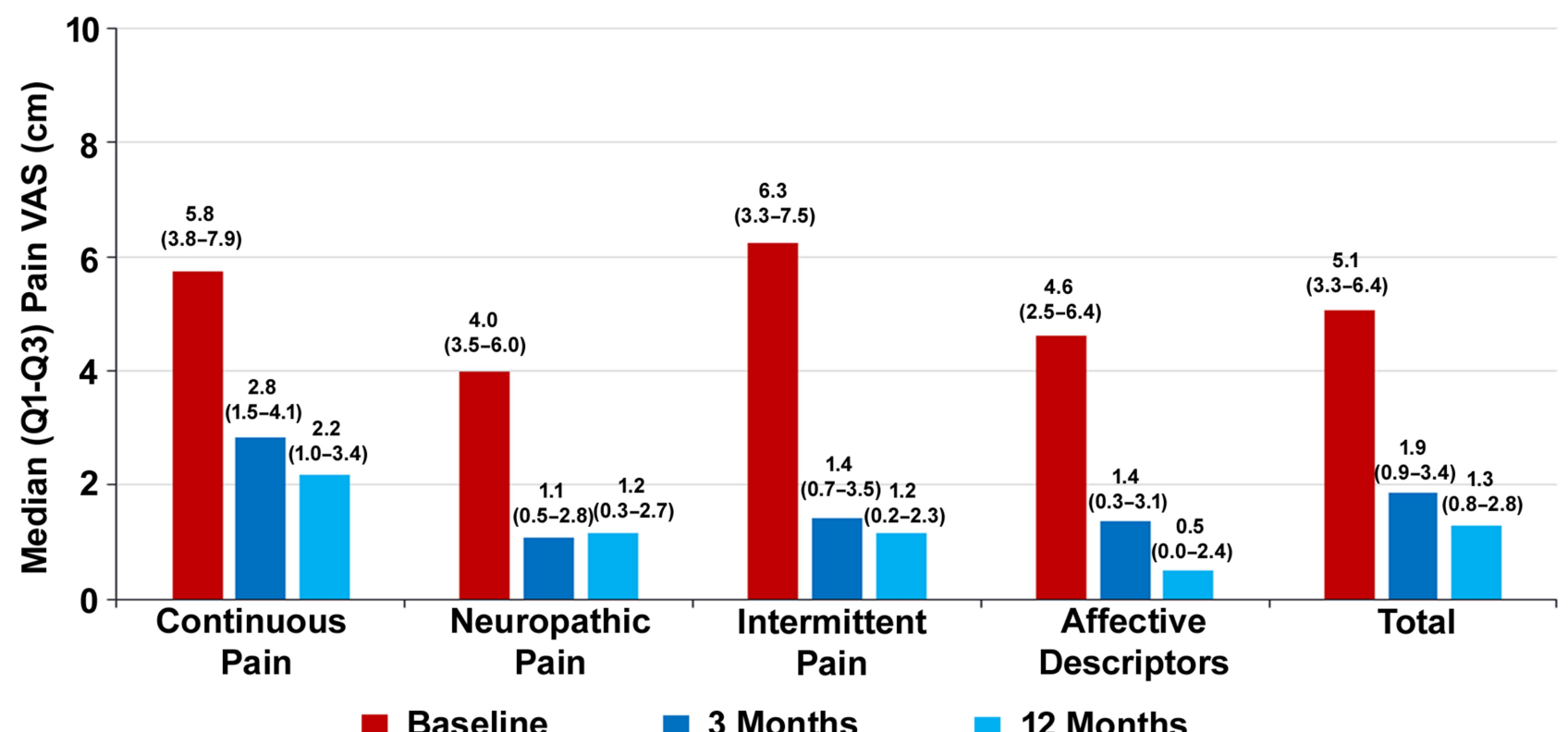

Figure 3 Reduction in SF-MPQ scores with $10 \mathrm{kHz}$ SCS; Data shown includes median (QI-Q3) at indicated assessment times.

opioid use and five subjects increased their opioid dose. One subject who was not taking opioids at baseline, was taking opioids at 15 morphine milligram equivalents (MME) dose at 12 months. Altogether, in subjects who increased their opioid dose at 12 months, the increase ranged between 5 and $30 \mathrm{MME}$, with an average increase of $18 \mathrm{MME}$ compared to baseline. Interestingly, subjects who increased their opioids to over $60 \mathrm{MME}$ at 12 months $(\mathrm{N}=2)$ were nonresponders ( $\geq 50 \%$ reduction) and did not even have clinically relevant pain reduction ( $\geq 30 \%$ reduction). Out of the remaining three subjects, one subject increased opioids by $5 \mathrm{MME}$ after six-month follow-up, one increased by $25 \mathrm{MME}$ and the third subject, who was not taking opioids at baseline increased opioids by 60 MME at three-month follow-up and then decreased the dose to $15 \mathrm{MME}$ at six- and 12-month follow-up. All these three subjects were responders at 12-month follow-up.

Overall, the difference in mean opioid dose between baseline (81.8 MME) and three months (77.2 MME) was not statistically significant $(p=0.49)$. However, the difference reached statistical significance at 12 months (61.0 MME, $p=0.04)$.

\section{Discussion}

People with moderate to severe UEP have difficulties in maintaining their lifestyle, exercise, sleep, performing household chores and social activities. ${ }^{20}$ This study suggests $10 \mathrm{kHz}$ SCS provides safe, substantial, and sustained pain relief in subjects with chronic UEP, along with clinically meaningful improvement in disability, functioning, and sleep.

A single case of possible, therapy-related extremity pain was reported by an investigator in this study. This was mild and transient, resolving after reprogramming and is consistent with recent prospective studies. ${ }^{15,16}$ Subjects were managed with reprogramming in all cases and did not require explant of the device. Similarly, AEs were without any neurological symptom changes and all device-related AEs were manageable (resolved after reprogramming). More importantly, despite positioning leads at C2-C7 vertebral level, there were no cases of lead migration that required lead repositioning in the current study or in the previous prospective studies. ${ }^{15,19}$ Previous retrospective studies using $10 \mathrm{kHz}$ SCS for upper limb and/or neck pain also reported no cases or low rates of lead migration. ${ }^{21-23}$ Lead migration is among the most concerning complications reported in prospective studies of cervical lead placement for management of pain. ${ }^{7,24-27} \mathrm{~A}$ systematic literature review of outcomes in patients with cervical SCS documented the rates for hardware malfunction (17.8\%), lead migration (13.9\%), lead fracture (6.7\%), pain over implant site $(4.4 \%)$ and infection $(2.2 \%){ }^{28}$ The $\mathrm{AE}$ rates reported in this study and in the previous studies evaluating $10 \mathrm{kHz}$ SCS for upper limb and neck pain treatment compare favorably with the published literature 
A

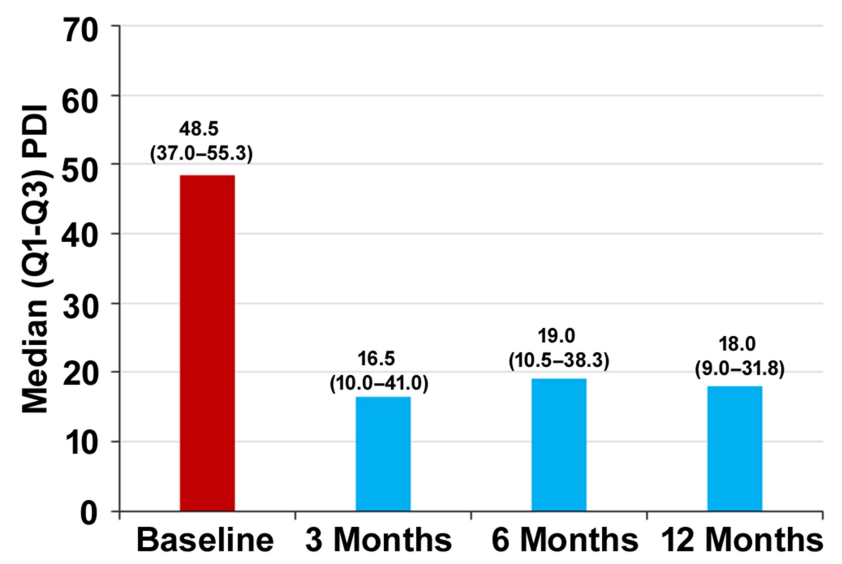

C

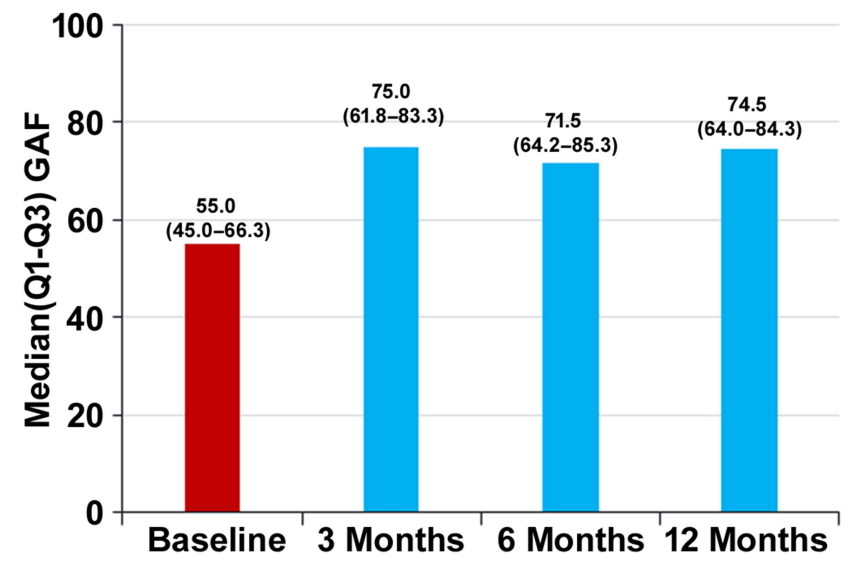

B

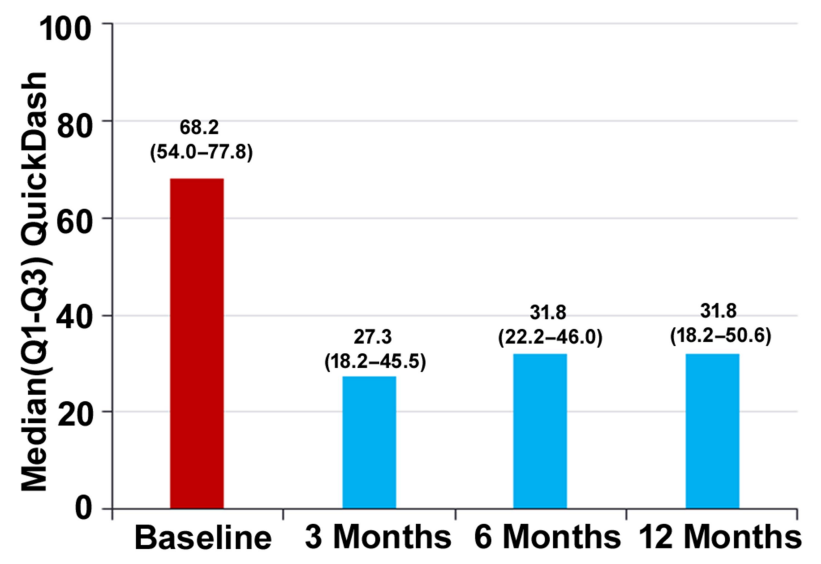

D

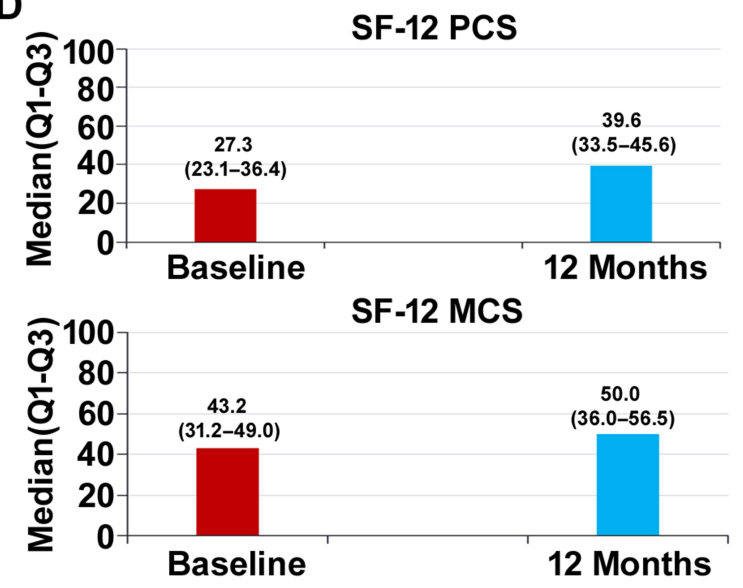

Figure 4 Improvement in quality of life and functioning with $10 \mathrm{kHz}$ SCS; (A) PDI scores, (B) QuickDASH, (C) GAF, (D) SF-12 scores (PCS and MCS subscale respectively), Data shown includes median (QI-Q3) at indicated assessment times.

and further support the safety of this therapy. Loss of efficacy and uncomfortable paresthesia are two common manifestations of lead migration and require revision surgery and/or explant of the device. However, because 10 $\mathrm{kHz}$ SCS is paresthesia-free, most cases of lead migration manifesting as decreased efficacy can be managed through reprogramming and very few cases require revision surgery or explant. ${ }^{21}$ Indeed, the rate of explant due to loss of efficacy is comparatively low with $10 \mathrm{kHz} \mathrm{SCS}^{29,30}$ and only one out of over 200 patients from six prospective and retrospective studies (including the current study) required an explant for loss of efficacy. ${ }^{15,16,21-23}$

Evidence for use of SCS in UEP is available from prospective studies testing traditional SCS and dorsal nerve root stimulation (DNRS) for upper limb and/or neck pain. ${ }^{26-28}$ Pain relief, responder rate, and remitter rates observed in the current study are substantial, sustained, and comparable to $10 \mathrm{kHz}$ SCS studies for treating chronic back and/or leg pain, such as randomized controlled trials, long-term retrospective evaluations, real-world data ${ }^{10,26-29,31-33}$ and an investigational $10 \mathrm{kHz}$ SCS study for treating upper limb and neck pain. ${ }^{15}$ Interestingly, outcomes improved over time and responses at 12 months were better than three months. While the improvement in efficacy at later time points could have been due to programming changes, data from a recently published upper limb and neck pain study showed that the number of programming sessions in fact decreased from three months to 12 months. ${ }^{15}$

Consistent with previous findings in patients with back and leg pain, results at three and 12 months revealed that 10 $\mathrm{kHz}$ SCS improved all components of the SF-MPQ including affective descriptors, disability scores (PDI and QuickDASH), and quality of life scales such as SF-12, GIC and satisfaction. Results from the current study indicate that $10 \mathrm{kHz}$ SCS helps subjects with UEP with continuous improvement in their sleep, reaching an approximately 20-point improvement in PSQ-3 scores at 


\section{PGIC - 3 Months}

A

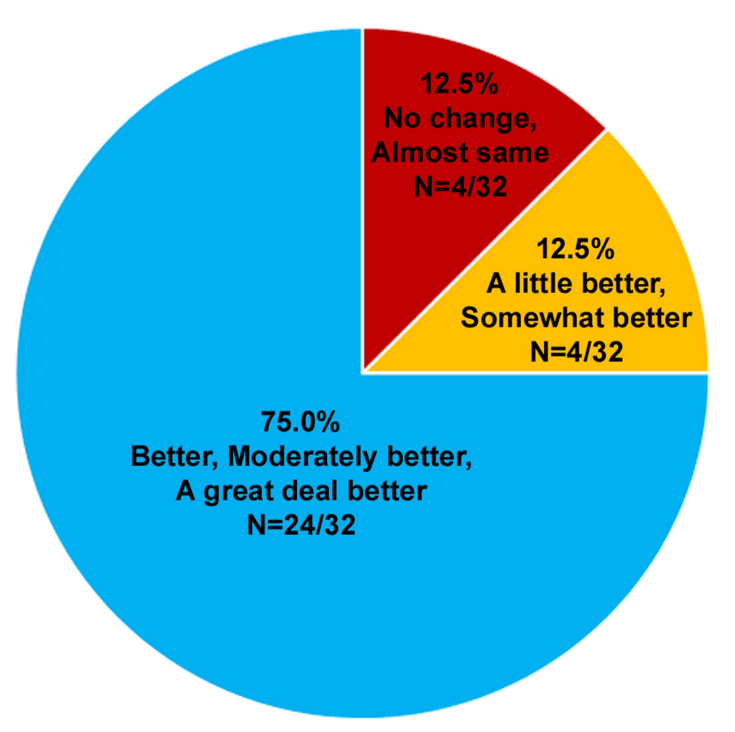

CGIC - 3 Months

C

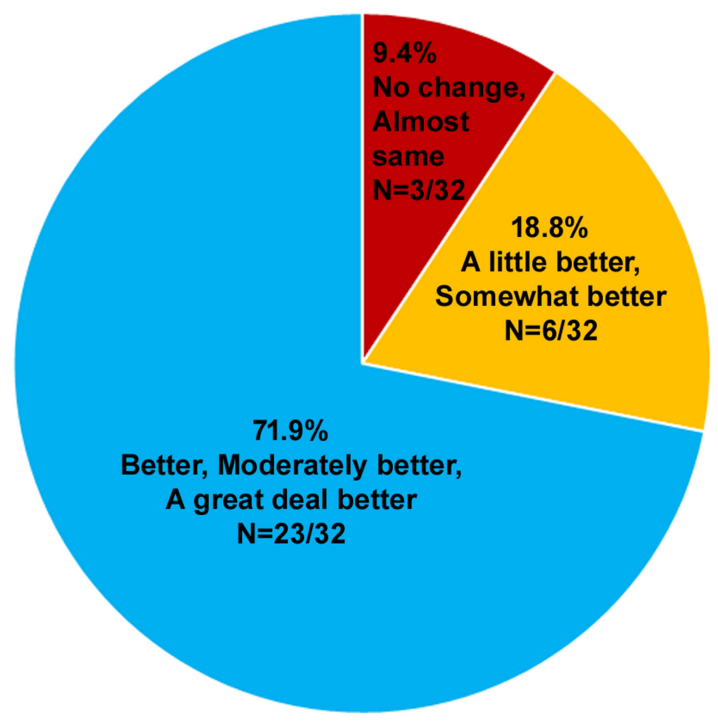

PGIC - 12 Months

B

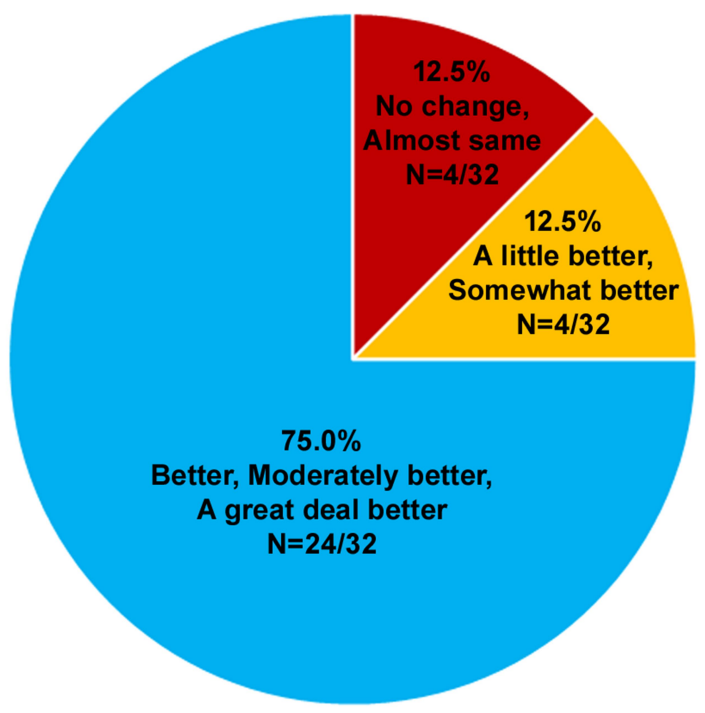

CGIC - 12 Months

D

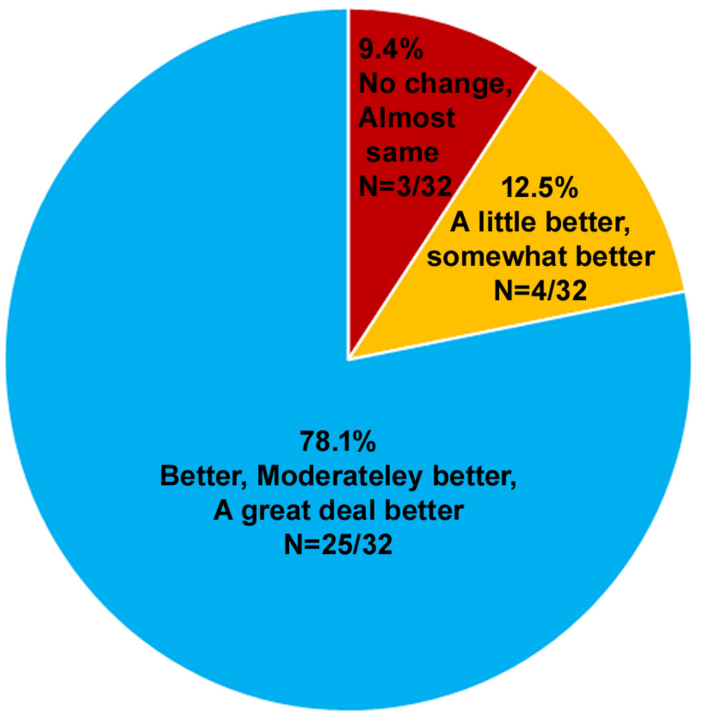

Figure 5 Patient and physician global impression of change with $10 \mathrm{kHz}$ SCS; (A-B) PGIC at three months and I2 months, (C-D) CGIC at three months and I2 months.

12-month endpoint. It is an interesting finding considering that about $40 \%$ of subjects either reduced or eliminated and $20 \%$ subjects increased their opioid dose at 12 -months. As opioids are known to interfere with sleep, further investigation is needed to understand whether improvement in sleep was due to decrease in opioid usage or because of direct effects of $10 \mathrm{kHz}$ SCS on sleep. Current findings on PSQ-3 scores and changes in opioid medication are similar to results from previously reported $10 \mathrm{kHz}$ SCS studies in chronic back and leg pain and retrospective analysis of real-world data. ${ }^{10,11,29,33,34}$
Durable and differentiated outcomes seen with $10 \mathrm{kHz}$ SCS treatment may be attributed to its unique mechanism of action. ${ }^{35-42}$ Using in vivo and ex vivo electrophysiological approaches, Lee et al reported that unlike low-intensity (sub-sensory threshold) $1 \mathrm{kHz}$ and $5 \mathrm{kHz} \mathrm{SCS}, 10 \mathrm{kHz}$ SCS selectively activated inhibitory interneurons in the spinal dorsal horn (DH) and proposed that low-intensity $10 \mathrm{kHz}$ SCS provided paresthesia-free pain relief possibly by activating the inhibitory interneurons without activating dorsal column fibers. ${ }^{35}$ Researchers from Chang Gung Memorial Hospital, Taiwan used spared nerve injury 

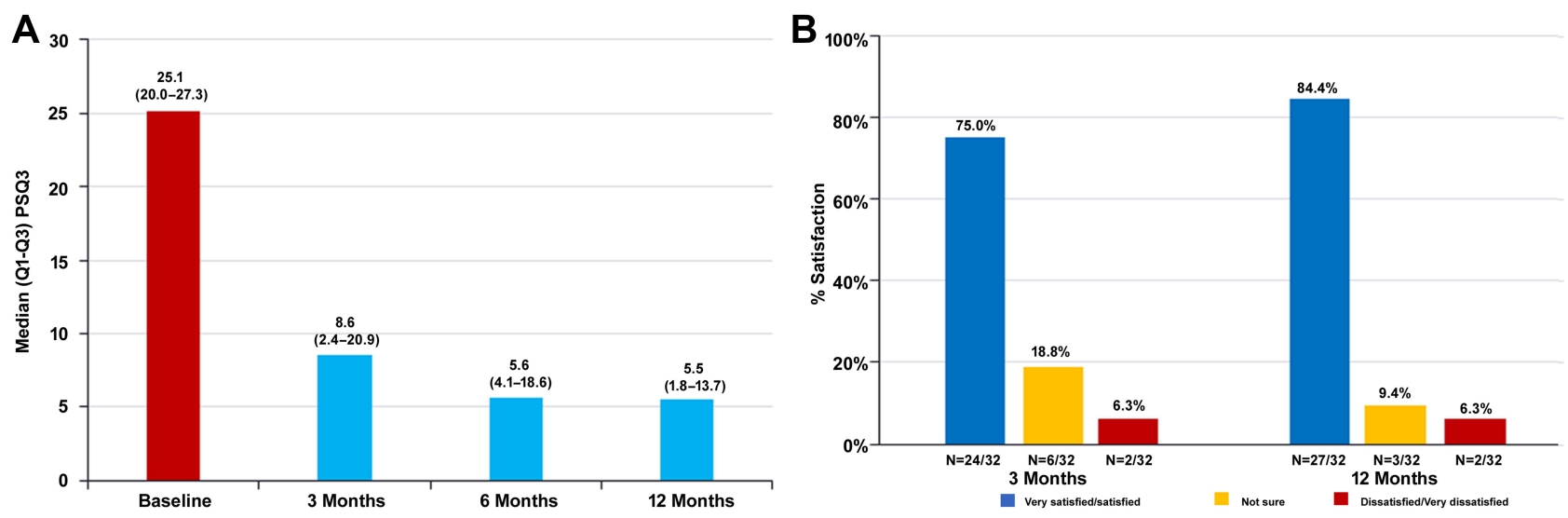

Figure 6 Improved sleep and subject satisfaction with 10 kHz SCS treatment; (A) PSQ-3 global scores at baseline and follow-up assessment (median: Q I-Q3), (B) Subject satisfaction at three and 12-month assessments.

(SNI)-induced neuropathic pain model in rats and showed that $10 \mathrm{kHz}$ SCS significantly reduced SNI-induced mechanical hyperalgesia compared to sham stimulation group. ${ }^{36}$ The study also showed significant reduction in activation of inflammatory kinases ERK1, ERK2, JNK1 and p38 in the dorsal root ganglia and the spinal DH in 10 $\mathrm{kHz}$ SCS group compared to sham stimulation group. Recently, the differences in mechanism of action between $10 \mathrm{kHz}$ SCS and 40-60 Hz paresthesia-based SCS was studied using 10-channel electroencephalogram (EEG) measurements in patients. ${ }^{40}$ Authors of the study recorded EEG changes in response to stimulation ON and OFF in chronic pain patients (four women, five men) during SCS surgery and demonstrated a unique shift in peak frequency from theta to alpha rhythms in $10 \mathrm{kHz}$ SCS group. Authors further showed a positive correlation between improvement in Oswestry disability index (ODI) scores and alpha/theta peak power ratio in frontal and somatosensory regions. Another study used resting stage functional magnetic resonance imaging (fMRI) to study brain connectome patterns in FBSS patients implanted with $10 \mathrm{kHz}$ SCS device and demonstrated increased connectivity between the anterior insula (affective salience network) and regions of the frontoparietal network and the central executive network. ${ }^{41}$ Authors of the fMRI study followedup with another study to test structural volumetric changes in chosen regions of interest of brain in patients with 10 $\mathrm{kHz}$ SCS implants and documented significant decreases in left and right hippocampus volume over time, which correlated with reduction in back pain intensity. ${ }^{42}$ Taken together, the findings demonstrate $10 \mathrm{kHz}$ SCS treatment is associated with unique objective physiological responses and sustained pain relief.

\section{Rationale for Choosing Lower Pain Relief Cutoff}

A lower pain relief cutoff $(\geq 40 \%)$ during the trial phase was chosen in the study over conventional cutoff $(\geq 50 \%)$ mainly because the duration of the trial was typically less than seven days. We anticipated that, in some subjects, we may not be able to program the optimal stimulation parameters to get the $\geq 50 \%$ pain relief during the trial period. As the main objective of the study was to understand the efficacy of $10 \mathrm{kHz}$ SCS over 12 months, we used a comparatively lower cutoff, which was higher than the clinically meaningful change ( $\geq 30 \%$ reduction). ${ }^{17}$ Two out of 33 subjects who received a permanent implant had $>40 \%$ and $<50 \%$ pain relief during the trial. One subject who had reported less than standard $\geq 50 \%$ pain relief during the trial reported sustained pain relief after permanent implant and improvements in other outcomes. The second subject achieved standard pain relief after one month of treatment with $10 \mathrm{kHz}$ SCS but reported loss of pain relief at later time points. The study does not recommend using lower than $50 \%$ pain relief as a cutoff during the trial period normal clinical practice and does not propose that using a longer trial period ( $>7$ days) is required for best outcomes.

Additional discussion on rationale for inclusion and exclusion criteria and the rationale for using subjects at follow-up visits for the efficacy analysis are presented in the Supplementary Digital Content. Discussion 1 and 2, respectively.

\section{Limitations}

This study was a pragmatic, postmarket, observational design intended to provide information on safety and efficacy 
to clinicians for counseling patients on the use of $10 \mathrm{kHz}$ SCS in the treatment of refractory upper extremity pain. As is the case in all such studies, without an appropriate randomized comparator arm there is an increased potential for various biases and confounding treatment influences to affect the results. Thus, any clinical decision making should carefully include consideration of these limitations. In addition, the findings are not universally generalizable to all patients with UEP and the demographics and various etiologies reported herein warrant careful inspection. Patient selection and treatment followed commercial standard of care at the individual sites and hence minimal selection bias, consistent with "realworld" practice was expected. Lack of a control group was partly addressed by comparing our findings with published results on the efficacy of $10 \mathrm{kHz}$ SCS from previous randomized controlled trials or real-world retrospective review.29,31,32 The findings from the current study encourages additional studies to address more scientific objectives.

\section{Conclusion}

To summarize, this study provides evidence that $10 \mathrm{kHz}$ SCS produces sustained and substantial pain relief in subjects with chronic, intractable pain of the upper extremities. Moreover, clinically meaningful improvement in functioning and sleep, and decrease in disability were observed. Further studies with appropriate design and sample size could confirm the efficacy of $10 \mathrm{kHz}$ SCS for UEP.

\section{Data Sharing Statement}

All the relevant de-identified data in this study has been included in the manuscript as part of the results. Authors cannot share the raw data from the patients due to privacy concerns.

\section{Acknowledgments}

We thank Ms Ami Shah, clinical consultant at Nevro for assistance with data analysis and Dr Madhuri Bhandaru for help with preparation of illustrations.

\section{Funding}

The study was sponsored by Nevro Corp.

\section{Disclosure}

Dr Kosek received research grants from Boston Scientific and Nevro Corp. Dr Rosen is a consultant to and received research grants from Flowonix, Saluda Medical, Biotronik, Medtronic, and Nevro. Dr Bromberg is a consultant and investor in Nevro and Mudjala. He also reports clinical educator/speakership from Medtronic, outside the submitted work. Dr Gulve is a consultant to Nevro Corp., Saluda Medical and received research grants from Boston Scientific, Abbott, Medtronic, and Mainstay Medical. Dr Esposito is a consultant to Nevro Corp., Abbott, Boston Scientific, Flowonix, and Vertiflex. Dr McRoberts is a consultant to Abbott. Dr Rotte is an employee of Nevro Corp. Mr Gliner was an employee of Nevro Corp. at the time the study was conducted and is now an independent consultant, Seattle, WA, USA. Dr Maneshi was an employee of Nevro Corp. at the time the study was conducted and is now affiliated with Abbott, Sunnyvale, CA, USA. Dr Subbaroyan was an employee of Nevro Corp. at the time the study was conducted and received stock options from Nevro Corp. He is now affiliated with GTX Medical, New York, NY, USA. The authors report no other conflicts of interest in this work.

\section{References}

1. Cote P, Cassidy JD, Carroll L. The Saskatchewan Health and Back Pain Survey. The prevalence of neck pain and related disability in Saskatchewan adults. Spine. 1998;23(15):1689-1698. doi:10.1097/ 00007632-199808010-00015

2. Makela M, Heliovaara M, Sievers K, Impivaara O, Knekt P, Aromaa A. Prevalence, determinants, and consequences of chronic neck pain in Finland. Am J Epidemiol. 1991;134(11):1356-1367. doi:10.1093/ oxfordjournals.aje.a116038

3. North RB, Kidd DH, Petrucci L, Dorsi MJ. Spinal cord stimulation electrode design: a prospective, randomized, controlled trial comparing percutaneous with laminectomy electrodes: part II-clinical outcomes. Neurosurgery. 2005;57(5):990-996.

4. North RB, Kidd DH, Olin J, Sieracki JM, Boulay M. Spinal cord stimulation with interleaved pulses: a randomized, controlled trial. Neuromodulation. 2007;10(4):349-357.

5. Foletti A, Durrer A, Buchser E. Neurostimulation technology for the treatment of chronic pain: a focus on spinal cord stimulation. Expert Rev Med Devices. 2007;4(2):201-214.

6. Oakley JC. Spinal Cord Stimulation in Axial Low Back Pain: solving the Dilemma. Pain Medicine. 2006;7:S58-S63.

7. Chivukula S, Tempel ZJ, Weiner GM, et al. Cervical and cervicomedullary spinal cord stimulation for chronic pain: efficacy and outcomes. Clin Neurol Neurosurg. 2014;127:33-41.

8. Penn DL, Zussman BM, Wu C, Sharan AD. Anterograde revision of cervical spinal cord stimulator paddle electrode: a case report. Neuromodulation. 2012;15(6):581-584.

9. Vallejo R, Kramer J, Benyamin R. Neuromodulation of the cervical spinal cord in the treatment of chronic intractable neck and upper extremity pain: a case series and review of the literature. Pain Physician. 2007;10(2):305-311.

10. Al-Kaisy A, Van Buyten J-P, Smet I, Palmisani S, Pang D, Smith T. Sustained Effectiveness of $10 \mathrm{kHz}$ High-Frequency Spinal Cord Stimulation for Patients with Chronic, Low Back Pain: 24-Month Results of a Prospective Multicenter Study. Pain Medicine. 2014;15 (3):347-354. doi:10.1111/pme.12294

11. Al-Kaisy A, Palmisani S, Smith TE, et al. Long-Term Improvements in Chronic Axial Low Back Pain Patients Without Previous Spinal Surgery: A Cohort Analysis of 10-kHz High-Frequency Spinal Cord Stimulation over 36 Months. Pain Med. 2018;19(6):1219-1226. doi:10.1093/pm/pnx237 
12. Gill JS, Asgerally A, Simopoulos TT. High-Frequency Spinal Cord Stimulation at $10 \mathrm{kHz}$ for the Treatment of Complex Regional Pain Syndrome: A Case Series of Patients With or Without Previous Spinal Cord Stimulator Implantation. Pain Pract. 2019;19(3):289294. doi:10.1111/papr.12739

13. De Carolis G, Paroli M, Tollapi L, et al. Paresthesia-Independence: an Assessment of Technical Factors Related to $10 \mathrm{kHz}$ ParesthesiaFree Spinal Cord Stimulation. Pain Physician. 2017;20(4):331-341.

14. Al-Kaisy A, Palmisani S, Smith T, Harris S, Pang D. The Use of 10Kilohertz Spinal Cord Stimulation in a Cohort of Patients With Chronic Neuropathic Limb Pain Refractory to Medical Management. Neuromodulation. 2015;18(1):18-23. doi:10.1111/ner.12237

15. Amirdelfan K, Vallejo R, Benyamin R, et al. High-Frequency Spinal Cord Stimulation at $10 \mathrm{kHz}$ for the Treatment of Combined Neck and Arm Pain: results From a Prospective Multicenter Study. Neurosurgery. 2020;87(2):176-185. doi:10.1093/neuros/nyz495

16. Verrills P, Salmon J, Russo M, Gliner B, Barnard A, Caraway D. $10 \mathrm{kHz}$ spinal cord stimulation for chronic upper limb and neck pain: australian experience. Eur Spine J. 2020. doi:10.1007/s00586-020-06480-x

17. Dworkin RH, Turk DC, Wyrwich KW, et al. Interpreting the clinical importance of treatment outcomes in chronic pain clinical trials: IMMPACT recommendations. J Pain. 2008;9(2):105-121. doi:10.10 16/j.jpain.2007.09.005

18. Dziura JD, Post LA, Zhao Q, Fu Z, Peduzzi P. Strategies for dealing with missing data in clinical trials: from design to analysis. Yale $J$ Biol Med. 2013;86(3):343-358.

19. Amirdelfan K, Gliner BE, Kapural L, et al. A proposed definition of remission from chronic pain, based on retrospective evaluation of 24month outcomes with spinal cord stimulation. Postgrad Med. 2019;131(4):278-286. doi:10.1080/00325481.2019.1592401

20. Gummesson C, Atroshi I, Ekdahl C, Johnsson R, Ornstein E. Chronic upper extremity pain and co-occurring symptoms in a general population. Arthritis Rheum. 2003;49(5):697-702. doi:10.1002/art.11386

21. El Majdoub F, Neudorfer C, Richter R, Schieferdecker S, Maarouf M. $10 \mathrm{kHz}$ cervical SCS for chronic neck and upper limb pain: 12 months' results. Ann Clin Transl Neurol. 2019;6(11):2223-2229. doi:10.1002/acn3.50915

22. Sayed D, Salmon J, Khan T, et al. $<\mathrm{p}>$ Retrospective Analysis of Real-World Outcomes of $10 \mathrm{kHz}$ SCS in Patients with Upper Limb and Neck Pain. J Pain Res. 2020; Volume 13(13):1441-1448. doi:10.2147/JPR.S257071

23. Russo M, Verrills P, Mitchell B, Salmon J, Barnard A, Santarelli D. High Frequency Spinal Cord Stimulation at $10 \mathrm{kHz}$ for the Treatment of Chronic Pain: 6-Month Australian Clinical Experience. Pain Physician. 2016;19(4):267-280.

24. Chan AK, Winkler EA, Jacques L. Rate of perioperative neurological complications after surgery for cervical spinal cord stimulation. $J$ Neurosurg Spine. 2016;25(1):31-38. doi:10.3171/2015.10.SPINE 15670

25. Forouzanfar T, Kemler MA, Weber WE, Kessels AG, van Kleef M. Spinal cord stimulation in complex regional pain syndrome: cervical and lumbar devices are comparably effective. Br J Anaesth. 2004;92 (3):348-353. doi:10.1093/bja/aeh072

26. Haider S, Owusu-Sarpong S, Peris Celda M, et al. A Single Center Prospective Observational Study of Outcomes With Tonic Cervical Spinal Cord Stimulation. Neuromodulation. 2017;20(3):263-268. doi:10.1111/ner.12483

27. Levine AB, Parrent AG, MacDougall KW. Cervical Spinal Cord and Dorsal Nerve Root Stimulation for Neuropathic Upper Limb Pain. Can J Neurol Sci. 2017;44(1):83-89. doi:10.1017/cjn.2016.294
28. Deer TR, Skaribas IM, Haider N, et al. Effectiveness of cervical spinal cord stimulation for the management of chronic pain. Neuromodulation. 2014;17(3):265-271. doi:10.1111/ner.12119

29. Stauss T, El Majdoub F, Sayed D, et al. A multicenter real-world review of $10 \mathrm{kHz}$ SCS outcomes for treatment of chronic trunk and/ or limb pain. Ann Clin Transl Neurol. 2019;6(3):496-507.

30. Al-Kaisy A, Royds J, Al-Kaisy O, et al. Explant rates of electrical neuromodulation devices in 1177 patients in a single center over an 11-year period. Reg Anesth Pain Med. 2020.

31. Kapural L, Yu C, Doust MW, et al. Novel 10-kHz High-frequency Therapy (HF10 Therapy) Is Superior to Traditional Low-frequency Spinal Cord Stimulation for the Treatment of Chronic Back and Leg PainThe SENZA-RCT Randomized Controlled Trial. Anesthesiology. 2015;123(4):851-860.

32. Kapural L, Yu C, Doust MW, et al. Comparison of 10-kHz HighFrequency and Traditional Low-Frequency Spinal Cord Stimulation for the Treatment of Chronic Back and Leg Pain: 24-Month Results From a Multicenter, Randomized, Controlled Pivotal Trial. Neurosurgery. 2016;79(5):667-677.

33. Amirdelfan K, Yu C, Doust MW, et al. Long-term quality of life improvement for chronic intractable back and leg pain patients using spinal cord stimulation: 12-month results from the SENZA-RCT. Qual Life Res. 2018;27(8):2035-2044.

34. Van Buyten JP, Al-Kaisy A, Smet I, Palmisani S, Smith T. Highfrequency spinal cord stimulation for the treatment of chronic back pain patients: results of a prospective multicenter European clinical study. Neuromodulation. 2013;16(1):59-65.

35. Lee KY, Bae C, Lee D, et al. Low-intensity, Kilohertz Frequency Spinal Cord Stimulation Differently Affects Excitatory and Inhibitory Neurons in the Rodent Superficial Dorsal Horn. Neuroscience. 2020;428:132-139.

36. Liao WT, Tseng CC, Wu CH, Lin CR. Early high-frequency spinal cord stimulation treatment inhibited the activation of spinal mitogenactivated protein kinases and ameliorated spared nerve injuryinduced neuropathic pain in rats. Neurosci Lett. 2020;721:134763.

37. Zannou AL, Khadka N, FallahRad M, Truong DQ, Kopell BH, Bikson M. Tissue Temperature Increases by a $10 \mathrm{kHz}$ Spinal Cord Stimulation System: phantom and Bioheat Model. Neuromodulation. 2019;25.

38. Caraway DL, Bradley K. Response to: "Tissue Temperature Increases by a $10 \mathrm{kHz}$ Spinal Cord Stimulation System: phantom and Bioheat Model". Neuromodulation. 2019;22(8):986-987.

39. Khadka N, Bikson M. Response to the Letter to the Editor by Caraway et al. on "Tissue Temperature Increases by a $10 \mathrm{kHz}$ Spinal Cord Stimulation System: phantom and Bioheat Model". Neuromodulation. 2019;22(8):988.

40. Telkes L, Hancu M, Paniccioli S, et al. Differences in EEG patterns between tonic and high frequency spinal cord stimulation in chronic pain patients. Clin Neurophysiol. 2020;131(8):1731-1740.

41. De Groote S, De Jaeger M, Van Schuerbeek P, et al. Functional magnetic resonance imaging: cerebral function alterations in subthreshold and suprathreshold spinal cord stimulation. J Pain Res. 2018;11:2517-2526.

42. De Groote S, Goudman L, Linderoth B, et al. A Regions of Interest Voxel-Based Morphometry Study of the Human Brain During HighFrequency Spinal Cord Stimulation in Patients With Failed Back Surgery Syndrome. Pain Pract. 2020;1:457. 


\section{Publish your work in this journal}

The Journal of Pain Research is an international, peer reviewed, open access, online journal that welcomes laboratory and clinical findings in the fields of pain research and the prevention and management of pain. Original research, reviews, symposium reports, hypothesis formation and commentaries are all considered for publication. The manuscript management system is completely online and includes a very quick and fair peer-review system, which is all easy to use. Visit http:// www.dovepress.com/testimonials.php to read real quotes from published authors. 